\title{
Full versus divided attention and implicit memory performance
}

\author{
GEZINUS WOLTERS and ARNO PRINSEN \\ Leiden University, Leiden, The Netherlands
}

\begin{abstract}
Effects of full and divided attention during study on explicit and implicit memory performance were investigated in two experiments. Study time was manipulated in a third experiment. Experiment 1 showed that both similar and dissociative effects can be found in the two kinds of memory test, depending on the difficulty of the concurrent tasks used in the divided-attention condition. In this experiment, however, standard implicit memory tests were used and contamination by explicit memory influences cannot be ruled out. Therefore, in Experiments 2 and 3 the process dissociation procedure was applied. Manipulations of attention during study and of study time clearly affected the controlled (explicit) memory component, but had no effect on the automatic (implicit) memory component. Theoretical implications of these findings are discussed.
\end{abstract}

Explicit tests of memory, like free recall and recognition, measure the intentional and conscious recollection of a previous experience. In contrast, implicit tests of memory measure a facilitation of performance due to the prior presentation of stimuli in the absence of intentional and conscious recollection of the experience itself (see, e.g., Schacter, 1987). Many experimental variables have been shown to differentially affect performances on explicit and implicit memory tests (for reviews, see, e.g., Richardson-Klavehn \& Bjork, 1988; Roediger \& McDermott, 1993). Such dissociations are of great theoretical importance because they seem to indicate the involvement of different memory systems or memory processes in explicit and implicit memory tasks.

One of the variables causing dissociative effects in explicit and implicit tests of memory is attention during study. In studying this variable, two situations have to be distinguished, namely presence versus absence of attention and full versus divided attention. Presence versus $a b-$ sence of attention refers to conditions in which subjects are either aware or unaware of the identity of the stimuli presented. Although there is much controversy regarding how to guarantee that a stimulus was truly unattended, some studies suggest that implicit memory for unattended information is possible (e.g. Jelicic, Bonke, Wolters, \& Phaf, 1992; Kihlstrom, Schacter, Cork, Hurt, \& Behr, 1990).

This study addresses the effect of full versus divided attention on implicit and explicit memory performance. This problem is related to the problem of presence versus absence of attention. If unattended stimuli can affect implicit memory performance, what happens if attention is focused on these stimuli, and when amount of process-

Correspondence should be addressed to G. Wolters, Department of Psychology, Leiden University, PO Box 9555, 2300 RB Leiden, The Netherlands (e-mail: wolters@rulfsw.LeidenUniv.nl). ing is enhanced beyond what is minimally required for identification?

Some experimental findings suggest that full attention enhances implicit memory performance. For example, studies by Eich (1984) and Phaf (1994) showed larger implicit memory effects for attended than for unattended stimuli. Other lines of research, however, seem to indicate that implicit memory performance is independent of the amount of processing following initial identification of stimuli. Studies by Greene (1986); Musen (1991); Neill, Beck, Bottalico, and Molloy (1990, Experiment 1); and Phaf and Wolters (1993, Experiment 3) all showed that increasing the duration of exposure, or of rehearsal, beyond about $1 \mathrm{sec}$ does not lead to further enhancement of implicit memory performance. Although an effect of presentation duration in a word fragment completion test was reported by Neill et al. (1990, Experiment 2), this finding may be criticized because subjects may have anticipated the test and may have used explicit retrieval strategies. Moreover, drugs like alcohol, benzodiazepines, and scopolamine, which supposedly reduce controlled processing and focusing of attention, have large adverse effects on explicit memory performance, but they seem to have little or no effect in repetition priming tasks (see, e.g., Polster, 1993). Also, conditions that have been linked to reduced information processing and inadequate allocation of attention, like old age and depression, have been found to cause decreased explicit but (almost) normal implicit memory performance (see, e.g., Jennings \& Jacoby, 1993; Roediger \& McDermott, 1993; Russo \& Parkin, 1993).

The most frequently used paradigm to study the effects of full versus divided attention on implicit and explicit memory is to manipulate attention by presenting stimuli in a study phase with or without a concurrent distracting task. Whereas generally adverse effects of a distracting secondary task are found in explicit memory performance, results with implicit memory tests have produced mixed 
results. No effects of distracting tasks on implicit memory performance were reported by Gardiner and Parkin (1990); Jacoby, Toth, and Yonelinas (1993); Jacoby, Woloshyn, and Kelley (1989); Koriat and Feuerstein (1976); Parkin, Reid, and Russo (1990); Parkin and Russo (1990); Russo and Parkin (1993); Wippich, Markert, Hannig, and Mecklenbräucker (1990); and Wippich, Schmitt, and Mecklenbräucker (1989). In contrast, decreased implicit memory performance in the presence of a concurrent task during study was found by Hawley and Johnston (1991) and by Pickering, Mayes, and Shoqeirat (1988). Results presented by Smith and Oscar-Berman (1990) are somewhat ambiguous. No effect of a dual-task condition was found on accuracy in a lexical decision task, but reaction times did show a reduced repetition priming effect.

Although the weight of the evidence seems to imply that implicit memory is unaffected by manipulations of attention, the conflicting results do not allow definite conclusions. The results summarized above may indicate that dividing attention during study can influence implicit memory performance, but only under certain conditions or with particular types of distractor tasks. In order to find out which factors may be involved in producing contradictory results, we have tried to classify the studies according to potentially relevant features. Although the studies varied widely in detail (i.e., type of stimuli, duration of retention interval, study conditions, and type of test), two features seemed especially relevant.

The first feature is the modality of stimulus presentation. Most studies finding no effect of dividing attention on implicit memory seem to have used tasks in which target and distracting stimuli were presented in different sensory modalities. Presenting the stimuli of the primary and the secondary tasks in the same modality may be expected to cause more interference and to enhance the possibility of finding an adverse effect of divided attention in implicit memory tests.

The second feature concerns the "difficulty" of the distracting task. As was suggested by Hawley and Johnston (1991), sometimes distracting tasks seem to be used that may not significantly reduce attention for the primary task. Although it is not possible to unambiguously judge the difficulty of the distractor tasks used, it seems that studies reporting decreased implicit memory performance in divided-attention conditions used rather demanding and difficult distracting tasks such as performing arithmetic calculations (see, e.g., Hawley \& Johnston, 1991; Pickering et al., 1988). In contrast, studies not finding dividedattention effects on implicit memory generally seem to have used less difficult perceptual classification tasks like detecting deviant tones or three odd digits in a row in a sequence of stimuli (see, e.g.. Jacoby et al., 1993; Parkin \& Russo, 1990). So, difficulty of the distracting tasks may also be a factor responsible for the contradictory findings.

The first experiment presented here was set up to further examine the conditions of divided attention under which performance in standard explicit (cued recall) and implicit (word stem completion) memory tests may be affected.
Doubts have been raised, however, regarding whether standard implicit and explicit tests of memory provide unconfounded measurements of conscious and unconscious influences of memory (e.g., Bowers \& Schacter, 1990; Richardson-Klavehn, Gardiner, \& Java, 1994). Such confounding seems to be absent in the "process dissociation procedure" (Jacoby, 1991; Jacoby et al., 1993). Therefore, two additional experiments are reported using this procedure. The aim of these experiments was to determine more clearly the extent to which manipulations of attention (Experiment 2) and study time (Experiment 3) affect controlled (explicit) and automatic (implicit) memory performance.

\section{EXPERIMENT 1}

Visually presented lists of words were studied with and without a distracting secondary task. The nature of the distractor task ("easy" or "difficult") and the modality of stimulus presentation in the distractor task (visual or auditory) were varied orthogonally over four groups of subjects. For each subject, half the words studied in the full- and divided-attention conditions were tested subsequently in a cued recall test, the other half in a word stem completion test.

\section{Method}

Subjects. Sixty-four undergraduate students at Leiden University participated as paid subjects. They were randomly assigned to four subgroups of 16 subjects. All subjects had normal hearing and normal or corrected-to-normal eyesight. None of the subjects had previously participated in experiments on implicit memory.

Design and Materials. Study condition (full vs. divided attention) and test type (cued recall vs. word stem completion) were manipulated within subjects. Type of distracting task (visual vs. auditory presentation, and easy vs. difficult) was manipulated between subjects; each of four subgroups of 16 subjects received one of the distractor tasks in the divided-attention condition. Four different distracting tasks were created by orthogonally combining easy or difficult conditions and visual or auditory presentation. Each subject studied two lists of words, one with and the other without a distracting task. Half the words of each list were tested in a cued recall test with word stems as cues, and the other half were used in a word stem completion test. The order of study condition (full vs. divided attention) and the order of tests (cued recall vs. word stem completion) was balanced over each subgroup of subjects.

The words to be used as stimuli were selected from a normative list providing spontaneous completion frequencies of two- or threeletter word stems (Phaf \& Wolters, 1991). A total of 120 nouns with unique word stems and spontaneous completion rates between 0.05 and 0.15 (average rate 0.07 ) were selected. For each word stem, at least eight other possible completions were possible. Obvious semantic relationships between words were avoided as much as possible. Half the words served as study items, and the other half were used as distractors in the word stem completion task (i.e., spontaneous completion of word stems to these nonstudied words provided the base rate). Words used as targets and distractors were balanced over subjects. The 60 target words were randomly divided into two study lists of 30 words, one of which was used in the fulland the other in the divided-attention condition. In the test phase, forms containing word stems were used in a word stem completion test and a cued recall test.

Procedure. This experiment consisted of four subexperiments with 16 subjects each. The subexperiments were alike except for 
the distracting task used. In the study phase of each subexperiment, two lists of 30 target words were presented to each subject. One list was presented without a distractor task (the full-attention condition), and the other with a distractor task (the divided-attention condition). In the full-attention condition, subjects were instructed to read the words aloud and to study them for the time remaining in anticipation of a memory test. In the divided-attention condition, presentation of the words was accompanied by one of the four distracting tasks. In this condition, subjects were instructed first to read the target word aloud, then to respond to the secondary task, and finally to study the words for the time remaining in anticipation of a memory test.

The words of each study list were presented one at a time, and in a different random order for each subject. Words were presented in capital letters in the middle of a computer screen connected to a BBC-B laboratory computer. Presentation time was $4 \mathrm{sec}$ with a 1 -sec interval between words. Before and after each list, 4 filler words (other than the 120 experimental words and with different word stems) were presented to avoid primacy and recency effects.

In each subexperiment, one of the four following distracting tasks was used to divide attention. In the visual/easy distractor task, a plus or a minus sign appeared to the right of the target word, and the subjects had to press a key corresponding to the sign. In the auditory/easy distractor task, either a high- or a low-pitched tone sounded for $0.5 \mathrm{sec}$ when a target word appeared; again, subjects had to press a corresponding key. In the visual/difficult distractor task, a two- or three-digit number (between 70 and 140) was presented to the right of the target word, and subjects had to decide whether or not the number was divisible by seven, responding by pressing a Yes or No key. Of the numbers half was divisible by seven (e.g., 105), the other half was not (e.g., 95). The auditory/difficult task was identical except that numbers were read to the subject.

The test phase consisted of a word stem completion test and a cued recall test. In the cued recall test, 30 word stems, 15 from each list studied either in the full- or the divided-attention condition, were given as cues. Subjects were instructed to use these cues to remember words from the lists studied before. In the completion test, the 30 target word stems corresponded with the other half of the words from both study lists. These stems were combined with all 60 word stems corresponding with distractor (i.e., nonstudied) words. The first 15 word stems all corresponded with distractor words. The remaining target and distractor word stems were randomly intermixed. In the stem completion test, subjects were told that this test was to determine the spontaneous completion rates of word stems. No mention was made of a possible relationship with the lists studied before. Subjects were instructed to complete the word stems as fast as possible to make a full word, using at least two additional letters and avoiding proper names and declensions of verbs. Since different and nonoverlapping sets of word stems were used in the two tests, interference or crossover effects between them are supposed to be minimal. Both the completion and the cued recall test were presented as forms on which word stems were printed in capital letters. Subjects wrote their responses on this form. After completing the cued recall test, subjects were questioned about whether they had been aware of the memory test character of the completion task. Although many subjects noted that they sometimes completed stems to words studied previously, none of them indicated awareness of the true nature of the test.

\section{Results and Discussion}

Analysis of performance on the distractor tasks showed that none of the subjects made any errors in the easy/ visual or easy/auditory conditions. The proportions of errors in the difficult/visual and difficult/auditory conditions were .13 and .16 , respectively. There were no significant effects of order of study condition or order of test type [cued recall first vs. second, $t(62)=-0.58$; word stem completion first vs. second, $t(62)=-0.87]$. Therefore, the data were pooled over these control conditions in the following analyses.

Average proportions correctly recalled and completed target words as a function of the difficulty of the distractor tasks are shown in Table 1 (since modality of the distractor tasks did not have any effect, data from the groups with corresponding visual and auditory distractor tasks were combined). The results of the word stem completion and cued recall tests were analyzed in separate analyses of variance (ANOVAs) with type of distractor task (easy or difficult and visual or auditory) as betweensubjects variables, and full or divided attention as a withinsubject variable.

Cued recall. Analysis of the cued recall data showed a significant main effect of attention $[F(1,60)=26.3$, $\left.M S_{\mathrm{e}}=3.5, p<.01\right]$. Overall, performance was better in the full- than in the divided-attention conditions (average proportions correct were .38 and .27 , respectively). A significant interaction was found between difficulty of distractor task and full/divided attention $[F(1,60)=8.8$, $\left.M S_{\mathrm{e}}=3.5, p<.01\right]$. No other factors approached significance, indicating that modality of presentation of distractor tasks did not have any effect. Inspection of Table 1 shows that in the divided-attention condition, performance was reduced more by the difficult than by the easy distractor task. A post hoc Newman-Keuls analysis revealed that the difference between the full- and both of the divided-attention conditions was significant $(p<.01)$. The difference between the easy and difficult dividedattention conditions was also significant $(p<.05)$.

Word stem completion. Average proportions correctly completed distractor words in the four subgroups were $.06, .07, .08$, and .08 . Overall the average was .07 , which is exactly the same as the average spontaneous completion rate in the normative study from which the words were selected. Average completion rates of target words in the full- and the combined divided-attention conditions were .25 and .21 , respectively. Both of these completion rates differed significantly from the completion rates of the distractor words $[t(63)=12.4, p<.01$ and $t(63)=11.3, p<.01]$. Thus, a large implicit memory effect occurred both in the full- and the divided-attention conditions.

\section{Table 1}

Proportions Correct (PC) and Standard Deviations for Cued Recall and Word Stem Completion as a Function of Fulland Divided-Attention Study Conditions (Experiment 1)

\begin{tabular}{lccccc}
\hline & \multicolumn{4}{c}{ Test Condition } \\
\cline { 2 - 3 } \multicolumn{1}{c}{ Study Condition } & \multicolumn{2}{c}{ Cued Recall } & & \multicolumn{2}{c}{ Stem Completion } \\
\cline { 2 - 3 } \cline { 5 - 6 } & PC & $S D$ & & $P C$ & $S D$ \\
\hline Full attention & .36 & .16 & .24 & .12 \\
Divided attention (easy) & .31 & .14 & .24 & .09 \\
Full attention & .40 & .16 & .27 & .12 \\
Divided attention (difficult) & .23 & .15 & .19 & .08 \\
\hline
\end{tabular}

Note-Average proportion of correctly completed nonstudied items (base rate) was 07 
An ANOVA on the word completion data revealed a main effect of attention $\left[F(1,60)=5.9, M S_{\mathrm{e}}=2.2, p<\right.$ $.05]$. Performance was better in the full- than in the divided-attention condition ( .25 vs. .21$)$. The interaction between difficulty of distractor task and full/divided attention was also significant $\left[F(1,60)=4.3, M S_{\mathrm{e}}=2.2\right.$, $p<.05]$. No other effects approached significance, and, again, modality of presentation of the distractor task did not have any effect. As can be inferred from Table 1, dividing attention with a difficult secondary task reduced stem completion more than did dividing attention with an easy distractor task. This conclusion was corroborated by the Newman-Keuls analysis. Only the difference between the full- and the difficult divided-attention condition was significant $(p<.05)$.

Inspection of Table 1 shows that the pattern of results in word stem completion closely matches that of cued recall. The data show similar effects of dividing attention during study in the explicit and the implicit tests of memory. However, whereas a difficult distractor task reduced performance both in cued recall and word stem completion, an easy distractor task caused a significant reduction of performance only in cued recall. These findings show that an "easy" distractor task may cause a dissociation effect-that is, a significant reduction of performance in an explicit memory test, but no effect in an implicit memory test.

The results of Experiment 1 suggest an explanation of discrepant findings regarding the effects of attention manipulations on explicit and implicit memory performance. According to this explanation, manipulations of attention during study have similar effects on explicit and implicit memory performance, but the effect size differs. Effects of divided attention in implicit memory tests show up only when more demanding secondary tasks are used.

Such a conclusion, however, may not be warranted because it cannot be ruled out that performance on implicit memory tests was contaminated by intentional (explicit) uses of memory (see, e.g., Bowers \& Schacter, 1990; Jacoby, 1991; Java, 1994; Merikle \& Reingold, 1991; Reingold \& Merikle, 1990; Russo \& Parkin, 1993). Spontaneous test awareness during implicit testing, for example, may sometimes prompt subjects to adopt an intentional retrieval strategy (e.g., Bowers \& Schacter, 1990). Despite our efforts to conceal the memory test character of the word stem completion test, contamination by explicit memory use cannot be ruled out. If such contamination did occur, it might be responsible for the similarity of the effects of attentional manipulations in cued recall and stem completion.

In order to exclude the possibility of confounding between implicit and explicit tests of memory, Jacoby (1991) suggested the process dissociation procedure. This procedure suggests a way to separate controlled (conscious or explicit) and automatic (unconscious or implicit) influences of memory. In a study by Jacoby et al. (1993. Experiments $1 \mathrm{~A}$ and $1 \mathrm{~B}$ ), the process dissociation procedure was used to study the effect of dividing attention on separate memory components. Jacoby et al. found that dividing attention did reduce the controlled memory component to zero, but it did not affect the automatic memory component.

To find out whether the reduction in word stem completion by dividing attention during study in Experiment 1 may be explained by a contamination with an explicit memory component, two additional experiments were performed using a variant of the process dissociation procedure. The standard process dissociation procedure controls for contamination by intentional retrieval. It does not control, however, for "involuntary explicit memory" responses - that is, items that are unintentionally retrieved but then consciously remembered. This is a conscious memory effect that may cause parallel effects of experimental manipulations on explicit and implicit memory tests (see, e.g., Richardson-Klavehn et al., 1994; Richardson-Klavehn, Lee, Joubran, \& Bjork, 1994). In the variant of the process dissociation procedure used in the following experiments (see Procedure, Experiment 2), not only intentionally retrieved items, but also unintentionally retrieved and subsequently recognized items, were discarded from the exclusion condition.

\section{EXPERIMENT 2}

In Experiment 1, an effect of manipulating attention during study on implicit memory showed up only in the difficult divided-attention condition. Therefore, in this experiment only this condition, and only the visual version of it, was compared with a full-attention condition. Instead of cued recall and stem completion tests, a process dissociation procedure was applied.

\section{Method}

Subjects. Thirty-two students from Leiden University served as paid subjects. None of them had participated in Experiment 1.

Design and Materials. Study condition (full vs. divided attention) and test type (inclusion and exclusion) were manipulated within subjects. The same set of 120 stimulus words of Experiment 1 was used, but 20 words with low spontaneous completion frequencies were replaced by words with higher completion frequencies. Mean spontaneous completion frequency in the whole set was 0.09 . The stimulus set was used to create two study lists of 30 words. The remaining 60 words were used for the distractor word stems. Only the visual version of the "difficult" distractor task was used. This task was the same as the one used in Experiment 1 . All subjects studied two lists of 30 target words, one without and the other with a distracting task. The order of the full- and divided-attention conditions was balanced over subjects, and the words used as targets or distractors were balanced over lists.

In the test phase, subjects were given an inclusion and an exclusion test. Unlike the procedure used by Jacoby et al. (1993), inclusion and exclusion tests were performed in subsequent blocks. The order of inclusion and exclusion tests was balanced overall, and also with respect to the order of studying in full- or divided-attention conditions. Both the inclusion and the exclusion tests consisted of two sets of 15 word stems corresponding to words studied in the fulland divided-attention conditions, respectively, and 30 word stems corresponding with nonstudied distractor words. The 60 word stems of each test were presented in random order on a form on which subjects wrote down their responses.

Procedure. Presentation of words and instructions regarding studying the words and performing the distractor task were the same 
as in Experiment 1. Instructions for the inclusion test required subjects to try to recall studied words using the word stems as cues. If they could not recall a studied word, they were to write down the first word that came to mind. In the exclusion test, subjects were also asked to try to recall a studied word and to generate the first word that came to mind if unsuccessful. Unlike Jacoby et al. (1993), who instructed subjects to avoid reporting remembered words, subjects were asked to write down each word, whether it was recalled or generated, when recall was unsuccessful. Additionally, however, they were instructed to mark (i.e., underline) a word as a word studied previously, if it was remembered or recognized after being generated. This altered procedure allowed for an independent check on the similarity of the proportion of explicitly remembered words in the exclusion test and the recollection proportion that is estimated from the inclusion and exclusion performance.

\section{Results and Discussion}

Subjects performed the distractor task as instructed. The average proportion of errors in the distractor task was 0.15 . This is comparable to the error proportion for this task in Experiment 1 (.13).

Average proportions of correctly completed target words in the inclusion and exclusion conditions are shown in Table 2. The proportion correct in the exclusion condition of course does not include the underlined (i.e., remembered/recognized) target words.

Analysis of the inclusion/exclusion data revealed a main effect of test instruction $\left[F(1,31)=57.8, M S_{\mathrm{e}}=5.6\right.$, $p<.01]$. As expected, more targets were given in the inclusion than in the exclusion test (.38 vs .18). More important, a significant interaction was found between study condition (full vs. divided attention) and test (inclusion vs. exclusion) $\left[F(1,31)=23.4, M S_{\mathrm{e}}=3.4, p<.01\right]$. The probability of completing stems with old words in the inclusion test was higher for the full-attention condition (.44) than for the divided-attention condition (.32). This pattern of results was reversed in the exclusion condition, in which more target words went undetected (i.e., were not underlined) in the divided-attention condition (.22) than in the full-attention condition (.15).

Estimates of controlled (C) and automatic (A) influences of memory were calculated per subject, and for the

Table 2

Average Proportions of Stems Completed (PC) and Standard Deviations With Target Items in the Inclusion and Exclusion Test, and Estimates of Controlled, Automatic, and Implicit Influences of Memory Averaged Over Subjects (Experiment 2)

\begin{tabular}{|c|c|c|c|c|}
\hline \multirow[b]{3}{*}{ Performance Measure } & \multicolumn{4}{|c|}{ Study Condition } \\
\hline & \multicolumn{2}{|c|}{ Full Attention } & \multicolumn{2}{|c|}{ Divided Attention } \\
\hline & $\mathrm{PC}$ & $S D$ & $\mathrm{PC}$ & $S D$ \\
\hline \multicolumn{5}{|c|}{ Test } \\
\hline Inclusion & .44 & .17 & .32 & .13 \\
\hline Exclusion & .15 & .08 & .22 & .11 \\
\hline $\mathrm{R} /$ exclusion & .29 & .17 & .06 & .07 \\
\hline \multicolumn{5}{|c|}{ Estimates } \\
\hline Controlled & .27 & .20 & .09 & .15 \\
\hline Automatic & .20 & .07 & .24 & .11 \\
\hline Implicit & .11 & .09 & .15 & .12 \\
\hline
\end{tabular}

Note - R/exclusion, average proportion of recalled and recognized items in the exclusion test. full- and divided-attention conditions separately, by applying the equations suggested by Jacoby et al. (1993; see also Toth, Reingold, \& Jacoby, 1994). Six subjects in the full-attention condition and 2 subjects in the dividedattention condition showed perfect exclusion performance, which prohibited calculations of $\mathrm{C}$ and $\mathrm{A}$.

To determine the actual implicit memory component (I), estimates of A have to be corrected for base rate (B). The base rate is the proportion of word stems completed to the corresponding distractor words. Overall, the proportion of correctly completed word stems corresponding with distractor words was .09 in the exclusion condition and .10 in the inclusion condition. As was pointed out to us (Masson, personal communication, 1996), the procedure in the exclusion condition allowed subjects to falsely claim that a distractor completion was an old word (i.e., the subject would not have given these completions under normal exclusion instructions). This might violate the assumption of identity of performance on distractor items across inclusion and exclusion conditions. False recognition of distractor words, however, occurred only rarely. Discarding them reduced the proportion of correct distractor words in the exclusion condition to .08 , which is still very similar to the normative spontaneous completion rate of .09 . Therefore, average rate of distractor word completions in the inclusion and exclusion conditions (.09) was used as an estimate of base rate.

Averages of the individually determined estimates of controlled, automatic, and implicit memory components are given in Table 2. Comparison of the proportion of underlined target words-a direct estimate of conscious or explicit memory - with the estimated proportions for $\mathrm{C}$ shows a very similar pattern of results.

As can be inferred from Table 2, the full-attention study condition produced a larger controlled memory component than did the divided-attention study condition [.27 vs. $.09 ; t(24)=2.96, p<.011$. In contrast, estimates of the automatic memory component did not show a significant difference between words studied in the full- or the divided-attention conditions [.20 vs. .24, respectively; $t(24)=0.97]$. Before concluding that dividing attention has no effect on the estimate of automatic processing, the power to detect an effect has to be determined. The largest effect that dividing attention could have with respect to reducing A would be to cause a drop from .20 (full attention) to .09 (baseline). Applying the rules for a power analysis on correlated pairs of means (Cohen, 1988; twotailed significance criterion is .05) gives a power of .93 . This is sufficiently high to accept the conclusion that dividing attention has no effect on the estimate of $A$.

These findings clearly contradict the results of Experiment 1 . They show that dividing attention does not affect the estimate of automatic influences of memory computed by excluding target completions that subjects either intentionally retrieved or unintentionally retrieved but then consciously remembered.

The manipulation of attention during study, as used in the experiments reported here, mainly seems to affect the effective study time. Therefore, it seems interesting to see 
whether a direct manipulation of study time has a similar effect on various aspects of memory. It would be expected that an increase in study time would affect controlled, but not automatic, influences of memory. Such a finding would corroborate the results of studies that have shown no increase of implicit memory performance when stimulus presentation time is increased beyond about $1 \mathrm{sec}$ (e.g., Greene, 1986; Musen, 1991).

\section{EXPERIMENT 3}

This experiment was set up to examine the effect of a manipulation of study time on controlled and automatic memory components. In addition, it provides an independent test of the reliability of the results obtained with the process dissociation procedure used in the previous experiment.

\section{Method}

Subjects. Thirty-two students from Leiden University served as paid subjects. None of the subjects had participated in any of the previous studies.

Design, Materials, and Procedure. Stimulus material and design were the same as in Experiment 2. Instead of full versus divided attention, however, study time was manipulated by varying the presentation time of stimuli. This variable was a within-subjects factor. Each subject studied two lists of 30 words. They were instructed to try to remember the words in anticipation of a recall test. The words were presented visually, one at a time, and in random order. Words of one list were presented for 1 sec (with 1 -sec intervals), and words of the second list were presented for $4 \mathrm{sec}$ (with 1 -sec intervals). The order of presentation times was balanced over subjects. Afterward each subject performed an inclusion and an exclusion test. Instructions for these tests were identical to the instructions described in Experiment 2. Both tests consisted of 30 stems corresponding to target words ( 15 each from the 1-sec and 4-sec lists) and 30 stems corresponding to distractor (i.e., nonstudied) words. The order of these tests was balanced with respect to the order of presentation times.

\section{Results and Discussion}

The proportion of word stems completed to the corresponding distractor words was 10 in the inclusion and .09 in the exclusion condition (excluding false recognitions; see Experiment 2). Again, these figures are quite similar to the normative spontaneous completion rate (.09). Average proportions of correctly completed target words in the inclusion and exclusion tests are shown in Table 3.

Analysis of the inclusion/exclusion data revealed a main effect of test: More target words were completed in the inclusion test (.39) than in the exclusion test $(.15)$ $\left[F(1.31)=111.9, M S_{\mathrm{e}}=4.6, p<.01\right]$. Moreover, test instruction and presentation time interacted $[F(1,31)=$ $\left.15.3, M S_{\mathrm{e}}=1.5, p<.01\right]$. The probability of completing stems with target words in the inclusion condition was higher for the 4-sec words than for the $1-\mathrm{sec}$ words $(.42$ vs. .36), whereas this pattern was reversed in the exclusion test (.14 vs. .16).

Estimates of controlled and automatic influences were again determined by subject. Results of 10 subjects in
Table 3

Average Proportions of Stems Completed (PC) and Standard Deviations With Target Items, and Average Estimates of Controlled, Automatic, and Implicit Influences of Memory (Experiment 3)

\begin{tabular}{llllll}
\hline & \multicolumn{4}{c}{ Study Condition } \\
\cline { 2 - 6 } \cline { 2 - 5 } Performance Measure & \multicolumn{2}{c}{$4 \mathrm{sec}$} & & \multicolumn{2}{c}{$1 \mathrm{sec}$} \\
\cline { 2 - 6 } \cline { 4 - 6 } & PC & $S D$ & & PC & $S D$ \\
\hline Inclusion & .42 & .14 & .36 & .14 \\
Exclusion & .14 & .09 & .16 & .08 \\
R/exclusion & .29 & .18 & .18 & .11 \\
& Estimates & & \\
Controlled & .29 & .18 & .18 & .14 \\
Automatic & .20 & .11 & .20 & .08 \\
Implicit & .10 & .13 & .10 & .10 \\
\hline
\end{tabular}

Note-R/exclusion, average proportion of recalled and recognized items in the exclusion test.

the 4-sec study condition and of 2 subjects in the 1-sec study condition could not be used because they showed perfect exclusion performance. Averages of individually determined controlled, automatic, and implicit memory components, and of the proportion of target words recalled/recognized in the exclusion test are shown in Table 3. These results show that the 4-sec study time condition caused a larger controlled memory component than did the $1-\mathrm{sec}$ study time $[.29$ vs. $.18 ; t(20)=2.55$, $p<.01]$. The automatic component, however, was not affected by the study time manipulation (.20 vs. .20$)$. The power of this latter test was .91 (see the procedure described in Experiment 2), so it can be concluded that presentation time had no effect on the estimate of the automatic memory component.

Because the full-attention condition in Experiment 2 was the same as the 4-sec presentation condition in this experiment, these data can be compared. The reliability of these results seems to be high, since both controlled $(.27$ vs. .29$)$ and automatic (.20 vs. .20$)$ memory components were very similar.

\section{GENERAL DISCUSSION}

The results of Experiment 1 show that the effects of full versus divided attention during study on performance in standard explicit and implicit memory tests can either be the same or dissociative. These findings suggest that contradictory results reported in the literature may be accounted for by the difficulty of distractor tasks used to manipulate attention, and that manipulations of attention can affect both explicit and implicit memory performance. In this experiment, however, conscious explicit memory effects in implicit memory performance cannot be ruled out. Both intentional retrieval and recognition of unintentionally retrieved (i.e., "spontaneously" generated) items were excluded in Experiments 2 and 3 by applying an altered version of the process dissociation procedure. In these experiments, large effects of attentional and study time manipulations on the controlled memory 
component were found, whereas the automatic memory component was not affected. These results corroborate previous findings showing that manipulations of attention during study, and of study time, do affect explicit, but not implicit, memory performance.

We suggest that the insensitivity of implicit memory performance for manipulations that have large effects on explicit memory performance can be most readily explained by an activation/elaboration account (see, e.g., Graf \& Mandler, 1984). According to this account, two types of processes have to be distinguished in stimulus encoding - activation and elaboration. The activation process consists of the automatic and nonconscious activation of existing memory representations corresponding to the stimulus presented. The subsequent elaboration process, which is accompanied by conscious awareness, is involved in encoding relations among the interpreted stimulus, the presentation context, and other stored knowledge. If it is assumed that the automatic activation process causes long-lasting strengthening of existing intraitem associations (see, e.g., Phaf \& Wolters, 1996), this strengthening suffices for implicit memory. It allows faster access when the same stimulus is presented in a later test, and it increases the chances of generating the stimulus when an incomplete stimulus has been given as a cue. In contrast, the attention- and time-demanding elaborative process is assumed to result in the creation of novel interstimulus and stimulus-context associations that are a prerequisite for explicit memory.

The assumption that strengthening intra-item associations (or a complete initial processing route preserving specific stimulus and encoding characteristics; see, e.g., Masson \& MacLeod, 1992) is an automatic consequence of an initial activation process can explain that data-driven implicit memory is found even when stimuli are presented very briefly to the unattended ear in a dichotic listening task or to anesthetized subjects. The only condition that would have to be met is the presence of sufficient stimulus energy to activate existing representations.

It may be assumed, furthermore, that amount of strengthening is restricted and that no further strengthening occurs once elaborative processing has taken over. This would explain why manipulations of attention and study time do not affect implicit memory performance. Our results do indeed suggest that implicit memory performance in data-driven tests quickly increases from zero to a maximum value (see also Greene, 1986, and Musen, 1991). In contrast, once elaborative processing has taken over, it may go on for a long time, creating an ever more extended and distinctive representational complex of novel associations among the stimuli, other existing knowledge, and the spatiotemporal context of stimulus presentation. Consequently, explicit memory performance will steadily increase. This elaborative process, however, is highly vulnerable to processing restrictions. Therefore, manipulations such as dividing attention and limitations of study time have large adverse effects on explicit memory performance. An interesting question for further study would be to determine whether or not manipulations of elaborative encoding affect performance on conceptually driven tests of implicit memory.

\section{REFERENCES}

Bowers, J. S., \& SCHACTER, D. L. (1990). Implicit memory and test awareness. Journal of Experimental Psychology: Learning, Memory, \& Cognition, 16, 404-416.

COHEN, J. (1988). Statistical power analysis for the behavioral sciences. Hillsdale, NJ: Erlbaum.

EICH, E. (1984). Memory for unattended events: Remembering with and without awareness. Memory \& Cognition, 12, 105-111.

Gardiner, J. M., \& PARKIN, A. J. (1990). Attention and recollective experience in recognition memory. Memory \& Cognition, 18, 579-583.

GRAF, P., \& MANDLER, G. (1984). Activation makes words more accessible, but not necessarily more retrievable. Journal of Verbal Learning \& Verbal Behavior, 23, 553-568.

GREENE, R. L. (1986). Word stems as cues in recall and completion tasks. Quarterly Journal of Experimental Psychology, 38A, 663-673.

HAWLEY, K. J., \& JoHNSTON, W. A. (1991). Long-term perceptual memory for briefly exposed words as a function of awareness and attention. Journal of Experimental Psychology: Human Perception \& Performance, 17, 807-815.

JACOBY, L. L. (1991). A process dissociation framework: Separating automatic from intentional uses of memory. Journal of Memory \& Language, 30, 513-541.

JACOBY, L. L., TOTH, J. P., \& Yonelinas, A. P. (1993). Separating conscious and unconscious influences of memory: Measuring recollection. Journal of Experimental Psychology: General, 122, 139-154.

JaCOBY, L. L., WoloshYN, V., \& KELLEY, C. (1989). Becoming famous without being recognized: Unconscious influences of memory produced by dividing attention. Journal of Experimental Psychology: General, 118, 115-125.

JAVA, R. I. (1994). States of awareness following word stem completion. European Journal of Cognitive Psychology, 6, 77-92.

Jelicic, M., Bonke, B., Wolters, G., \& PHAF, R. H. (1992). Implicit memory for words presented during anaesthesia. European Journal of Cognitive Psychology, 4, 7I-80.

JenningS, J. M., \& JACOBY, L. L. (1993). Automatic and intentional uses of memory: Aging, attention, and control. Psychology \& Aging, 8, 283-293.

Kihlstrom, J. F., Schacter, D. L., Cork, R. C., Hurt, C. A., \& Behr, S. E. (1990). Implicit and explicit memory following surgical anesthesia. Psychological Science, 1, 303-306.

Koriat, A., \& Feuerstein, N. (1976). The recovery of incidentally acquired information. Acta Psychologica, 40, 463-474.

Masson, M. E. J., \& MACLEOD, C. M. (1992). Reenacting the route to interpretation: Enhanced perceptual identification without prior perception. Journal of Experimental Psychology: General, 121, 145 176.

Merikle, P. M., \& Reingold, E. M. (1991). Comparing direct (explicit) and indirect (implicit) measures to study unconscious memory. Journal of Experimental Psychology: Learning, Memory, \& Cognition, 17, 224-233.

Musen, G. (1991). Effects of verbal labeling and exposure duration on implicit memory for visual patterns. Journal of Experimental Psychology: Learning, Memory, \& Cognition, 17, 954-962.

Neill, W. T., BeCK, J. L., Bottalico, K. S., \& Molloy, R. D. ( 1990 ). Effects of intentional versus incidental learning on explicit and implicit tests of memory. Journal of Experimental Psychology: Learning, Memory, \& Cognition, 16, 457-463.

Parkin, A. J., Reid, T. K., \& Russo, R. (1990). On the differential nature of implicit and explicit memory. Memory \& Cognition, 18. 507514.

PARKIn, A. J., \& Russo, R. (1990). Implicit and explicit memory and the automatic/effortful distinction. European Journal of Cognitive PSychology, 2, 71-80.

PhaF, R. H. (1994). Learning in natural and connectionist systems. London: Kluwer. 
PHAF, R. H., \& Wolters, G. (1991). Spontaneous completion frequencies for 168 two and three letter word stems [Internal report]. Leiden University.

PhaF, R. H., \& Wolters, G. (1993). Attentional shifts in maintenance rehearsal. American Journal of Psychology, 106, 353-382.

PhaF, R. H., \& Wolters, G. (1996). Elaboration effects in implicit and explicit memory tests. Psychological Research, 58, 284-293.

Pickering, A. D., Mayes, A. R., \& Shoqeirat, M. (1988). Priming tasks in normal subjects: What do they reveal about amnesia? In M. M Gruneberg, P. E. Morris, \& R. N. Sykes (Eds.), Practical aspects of memory: Current research and issues (Vol. 2, pp. 58-63). New York: Wiley.

PolsTER, M. R. (1993). Drug-induced amnesia: Implications for cognitive neuropsychological investigations of memory. Psychological Bulletin, 114, 477-493.

ReINGOLD, E. M., \& MerikLE, P. M. (1990). On the inter-relatedness of theory and measurement in the study of unconscious processes. Mind \& Language, 5, 9-28.

RichaRdSON-KLAVEHN, A., \& BJoRK, R. A. (1988). Measures of memory. Annual Review of Psychology, 39, 475-543.

Richardson-Klavehn, A., Gardiner, J. M., \& Java, R. I. (1994). Involuntary conscious memory and the method of opposition. Memory, 2, 1-29.

Richardson-Klavehn, A., Lee, M. G., Joubran, R., \& Bjork, R. A (1994). Intention and awareness in perceptual identification priming. Memory \& Cognition, 22, 293-312.

RoEDIGER, H. L., \& MCDERMOTT, K. L. (1993). Implicit memory in normal human subjects. In H. Spinnler \& F. Boller (Eds.), Handbook of neuropsychology (Vol. 8, pp. 63-131). Amsterdam: Elsevier.
Russo, R., \& PARKIN, A. J. (1993). Age differences in implicit memory: More apparent than real. Memory \& Cognition, 21, 73-80.

SCHACTER, D. L. (1987). Implicit memory: History and current status Journal of Experimental Psychology: Learning, Memory, \& Cognition, 13, 501-518.

Smith, M. E., \& Oscar-Berman, M. (1990). Repetition priming of words and pseudowords in divided attention and in amnesia. Journal of Experimental Psychology: Learning, Memory, \& Cognition, 16, 1033-1042.

Toth, J. P., Reingold, E. M., \& JACOBY, L. L. (1994). Toward a redefinition of implicit memory: Process dissociations following elaborative processing and self-generation. Journal of Experimental Psychology: Learning, Memory, \& Cognition, 20, 290-303.

WipPich, W., Markert, A., Hannig, G., \& MecklenbräUCKer, S. (1990). Erinnerungen an neue Assoziationen [Remembering new associations]. Zeitschrift für experimentelle und angewandte Psychologie, 37, 153-178.

WiPPICH, W., SChmitt, R., \& Mecklenbräucker, S. (1989). Untersuchungen zur Wirkung geteilter Aufmerksamkeit auf explizite und implizite Behaltensmasse [Studies of the effect of divided attention on explicit and implicit memory performance]. Zeitschrift für experimentelle und angewandte Psychologie, 36, 328-348.

(Manuscript received April 16, 1996; revision accepted for publication October 24, 1996.) 